\title{
CUSTOMER SATISFACTION SEBAGAI VARIABLE YANG MEMEDIASI SERVICE PERFORMANCE TERHADAP CUSTOMER LOYALTY PADA BIMBINGAN BELAJAR CRYSTAL LEARNING CENTER DI KOTA JAYAPURA
}

Khusnul Khotimah ${ }^{1}$, Imran S M Nur ${ }^{2}$, Muhamad Aldrin Akbar ${ }^{3}$, Badriah ${ }^{4}$

1,2,3,4 Program Studi Manajemen, Fakultas Ekonomi dan Bisnis, Universitas Yapis Papua, Jayapura, Indonesia Jalan Sam Ratulangi no 11, Jayapura, 99113, Indonesia

e-mail: khusnul.khotimah1978@gmail.com

\begin{abstract}
Abstrak
Penelitian bertujuan untuk mendeteksi apakah terdapat hubungan antara service performance mempengaruhi customer loyalty dengan customer satidfaction adalah variable yang memediasi. Metode penelitian adalah kuantitaif dan kualitatif, jenis penelitian asosiatif. Populasi dalam penelitian merupakan seluruh pelanggan bimbingan belajar chrystal learning center yang berjumlah 144 orang. Sampel berjumlah 106 orang yang di ambil dengan rumus slovin, dengan teknik sampel purposive sampling jenis judgment sampling. Tools dalam penelitian ini menggunakan Amos 25 dan di dukung dengan sobel test. Hasil menunjukkan hubungan indirect $0,125>$ direct 0,027 , dan hasil sobel test nilai $\mathrm{Z}=2,0103>$ dari 1,983. Artinya terdapat hubungan antara service performance berpengaruh customer loyalty dengan customer satisfactionan yang dimediasi oleh customer satisfaction.
\end{abstract}

Kata Kunci : Service Performance, Customer Loyalty and Customer Satisfaction.

\section{PENDAHULUAN}

Salah satu pelaku bisnis yang tetap mempertahankan eksistensinya ditengah masa pandemic yaitu pelaku bisnis dalam bidang jasa seperti bimbingan belajar, karena dalam dunia pendidikan saat ini para siswa-siswi membutuhkan pembimbingan yang sangat ekstra. Pandemic covid-19 menjadi penyebab pelajar dituntut untuk belajar secara online. Hal tersebut yang menimbulkan kecemasan orang tua terhadap prestasi anak-anak nya, dalam upaya untuk meningkatkan semangat belajar anak, dan menjadi pilihan yang tepat dan merupakan kewajiban orang tua, yaitu memprioritaskan kebutuhan belajar anaknya. Terkait hal tersebut bimbingan belajar yang tetap beraktivitas ditengah kondisi saat ini yaitu bimbingan belajar crystal learning center karena bimbingan belajar crystal learning center selalu berusaha agar tetap memberikan pelayanan kepada konsumennya. Hal tersebut dilakukan agar pelayanan yang diberikan dapat menciptakan customer loyalty yang mana kesetiaan dari seorang konsumen membutuhkan waktu yang tidak sebentar, namun melalui suatu proses belajar pelanggan dalam menilai pelayanan yang di berikan. Artinya bahwa ketika pelanggan mendapatkan apa yang diinginkan, sehingga re-purchase dapat terus dilakukan, hal itulah yang kemudian dikenal dengan kesetiaan pelanggan (Customer Loyalty) dan begitupun sebaliknya apabila pelanggan tidak mendapatkan produk atau jasa yang bisa memuaskan, ini menjadikan konsumen untuk susah berhenti sampai ia benar-benar menemukan produk atau jasa yang memenuhi kriteria mereka. Bimbingan belajar crystal learning center selalu berupaya untuk membantu prestasi muridnya dan tetap memberikan pelayanan yang baik untuk meraih kepercayaan pelanggannya. Terkait masalah ini, belum bisa untuk tolak ukur dalam menciptakan loyalitas pelanggan. Berikut tabel yang menunjukkan adanya fenomena gap yang terjadi sebagai berikut :

Tabel Jumlah Murid Bimbingan Belajar

Crystal Learning Center Tahun 2019 dan Tahun 2020

\begin{tabular}{|c|c|c|c|}
\hline $\begin{array}{c}\text { Oktober } \\
\mathbf{2 0 1 9}\end{array}$ & Jumlah & $\begin{array}{c}\text { Oktober } \\
\mathbf{2 0 2 0}\end{array}$ & Jumlah \\
\hline TK/PAUD & 24 Murid & TK/PAUD & 17 Murid \\
\hline SD & 126 Murid & SD & 80 Murid \\
\hline SMP & 44 Murid & SMP & 32 Murid \\
\hline SMA & 27 Murid & SMA & 15 Murid \\
\hline Jumlah & 221 Murid & Jumlah & 144 Murid \\
\hline
\end{tabular}

Sumber: Data diolah, 2020

Copyright $\odot$ Authors. This is an open access article distributed under the Attribution-

NonCommercial-

ShareAlike 4.0 International (CC BY-NC-SA 4.0), which permits unrestricted use, distribution, and reproduction in any medium, provided the original work is properly cited. 
Selain fenomena gap yang terjadi di bimbingan belajar crystal learning center ada pula research gap pada penelitian terdahulu yang mengacu pada hubungan service performance terhadap loyalitas pelanggan yang di lakukan oleh beberapa peneliti seperti Purwanto, 2015; Sofi et al.,2017; Ratmawaty, 2016; dan Jamaluddin, 2019.

\section{Rumusan Masalah}

Apakah service performance mempunyai hubungan dengan customer loyalty jika customer satisfaction sebagai mediasi pada Bimbingan Belajar Crystal Learning Center Di Kota Jayapura

\section{Tujuan Penelitian}

Untuk mengetahui service performance berpengaruh dengan customer loyalty dan customer satisfaction adalah variabel yang memediasi di Bimbingan Belajar Crystal Learning Center di Kota Jayapura.

\section{Manfaat Penelitian}

Penelitian ini kedepannya di harapkan dapat berkontribusi terhadap Perusahaan, Akademik dan Peneliti.

\section{TINJAUAN PUSTAKA DAN PERUMUSAN HIPOTESIS Kajian Pustaka}

Penelitian ini didasarkan pada manajemen pemasaran sebagai grand theory yang kemudian diturunkan dalam middle theory yaitu marketing mix dan perilaku konsumen

(Customer Behavior) dengan applied theory. Penelitian ini memakai customer loyalty, service performance, dan customer satisfaction.

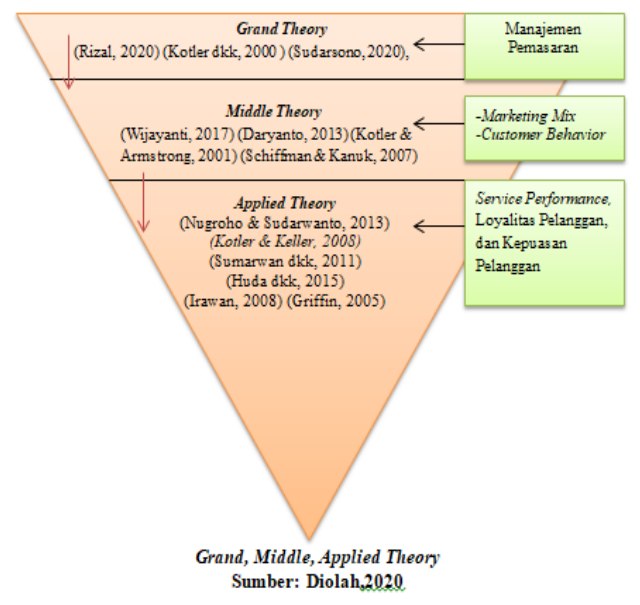

\section{Service Performance}

Cronin dan Taylor (1994) mengemukakan bahwa Pelayanan yang dirasakan oleh seorang pelanggan berupa kinerja pelayanan merupakan Service performance. Pengertian ini mengandung asti bahwa sevice performance adalah kinerja dari layanan yang diberikan sebagai pengguna jasa dan menilai dari kualitas layanan yang diberikan kepada pelanggan. Hal ini service performance yang di maksud Cronin dan Taylor merupakan ukuran dari sisi kualitas layanan yang dirasakan penerimanya dan dengan tetap menggunakan dasar lima dimensi parasuraman et al, yaitu yang merupakan Indikator service performance antara lain : Tangibility, Reliability, Responsiveness, Assurance, dan Emphaty.

\section{Customer Satisfaction}

Hubungan antara customer satisfaction dan customer loyalty tidak bersifat proporsional. Suatu usaha dinilai memiliki perhatian, jika customer satisfactionnya secara teratur melakukan pengecekkan, dikarenakan modal agar di senangi konsumen antara lain satisfaction, menunjukan rasa bahagia dari yang merasakan layanan, dimana hal ini muncul melalui harapan dari sesuatu yang di rasakan. Dimana hasil kecil dari harapan, konsumen belum senang, begitupun sebaliknya senadainya harapan sesuai yang di rasakan maka pelanggan akan merasa tercukupi (Kotler \& Keller, 2008). Customer satisfaction dapat di katakana sebagai rasa bahagia dari seorang customer dengan membandingkan kesan dari kualitas pelayanan pada harapan produk (Huda et al., 2015). Customer satisfaction merupakan presepsi menurut Irawan (2008) dari suatu product yang mewakili harapan. Berdasarkan definisi tersebut dapat diambil 
kesimpulan jika customer satisfaction merupakan presepsi pelanggan terhadap hasil yang dirasakan oleh pelanggan baik perasaan senang maupun kecewa atas pelayanan yang telah diberikan pennyedia jasa terhadap pengguna jasa. Indikator customer satisfaction antara lain: Perasaan puas, Terpenuhinya harapan setelah membeli produk, dan Selalu membeli produk.

\section{Customer Loyalty}

Dalam hal ini customer loyalty adalah mereka yang selalu berulang melakukan pembelian, bahkan lebih dari 10 kali dan berlangganan dalam waktu jangka panjang. Ketika seorang pelanggan loyal berarti mereka percaya dengan kualitas produk ataupun jasa. Customer loyalty dapat di tunjukkan bagi orang yang terus menerus melakukan pembelian berulang bagi suatu produk (Sumarwan et al., 2011). Customer loyalty adalah perasaan senang dari product yang di gunakan dan terus melakukan pembelian berulang. Adapula yang menyatakan bahwa customer loyalty itu sebuah kesepakatan jangka panjang untuk kembali membeli melalui patron yang berulang (Huda et al., 2015). Griffin pada tahun 2005 mengemukakan wujud dari perilaku suatu keputusan dalam pembelian product adalah customer loyalty. Indikator customer loyalty antara lain: Pembelian yang berulang, jasa diantara pilihan produk, mencoba mengenalkan pada masyarakat lain, dan tahan akan dayatarik pesaingnya.

\section{MODEL EMPIRIK}

Kerangka konseptual merupakan hubungan antara teori-teori yang mendukung penulis dalam melakukan penelitian guna dijadikan tolak ukur dalam penyusunan sistematis penelitian.

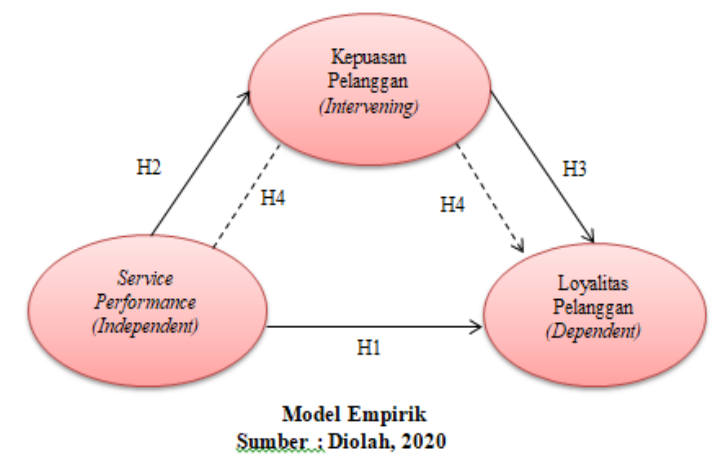

\section{HIPOTESIS}

Dari rumusan masalah dapat diperoleh :

$\mathbf{H}_{1}$ Service performance mempunyai hubungan dengan customer loyalty

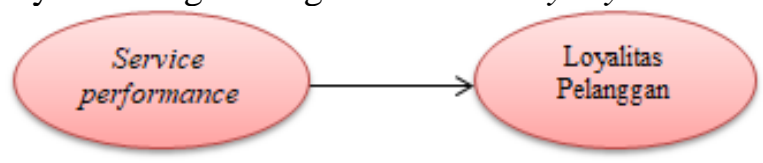

$\mathbf{H}_{2}$ Service performance berpegaruh dengan Customer satisfaction

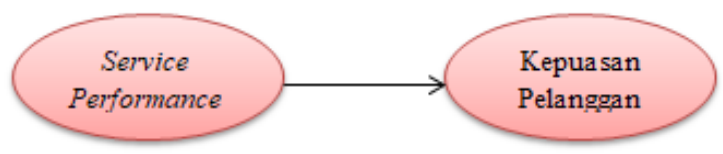

$\mathbf{H}_{3}$ Customer satisfaction terdapat keterkaitan customer loyalty

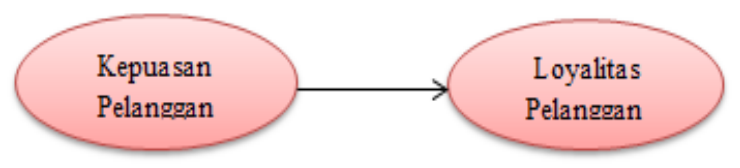

$\mathbf{H}_{4}$ Service Performance lebih baik terhubung dengan customer loyalty melalui perantara Customer satisfaction.

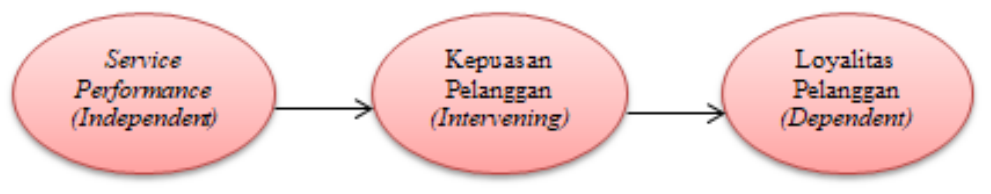




\section{METODE}

\section{Jenis dan Rancangan}

Asosiatif adalah jenis penelitian yang di gunakan, yang mana jenis dari suatu reserach yang biasa digunakan dalam menganalisis keterkaitan antara variabel dependen dengan variabel independen (Carsel, 2018). Rancangan digunakan peneliti (Sangadji \& Sopiah, 2010) adalah ; memilah masalah penelitian; observation; perumusan masalah; rumuskan hipotesis yang ada; analisis pendekatan; sumber data dalam variabel; Instrumen di susun dan di tentukan; pengumpulan data; data di analisis; kesimpulan; dan laporan dibuat.

\section{Lokasi dan Waktu Penelitian}

Kegiatan penelitian dilakukan kepada siswa aktif bimbingan belajar Crystal Learning Center di Perumahan Jaya Asri Blok Ac No. 11 A di Kota Jayapura, yang dilakukan dimulai dari awal Oktober 2020 sampai dengan Januari 2021.

\section{Populasi \& Sampel}

Siswa aktif bimbingan belajar Crystal Learning Center Di Kota Jayapura yaitu sebanyak 144 orang (murid), jumlah tersebut termasuk 98 murid online dan 46 murid offline, merupakan jumlah populasi. Sementara penentuan jumlah sampel yang digunakan adalah menggunakan formula Slovin, dikarenakan jumlah populasi yang diketahui melebihi 100 responden.

Formula Slovin (Riyanto \& Hartawan, 2020), yaitu:

$$
\begin{gathered}
n=\frac{N}{1+n e^{2}} \\
n=\frac{144}{1+(144)(0,05)^{2}}=105,8=106 \text { murid }
\end{gathered}
$$

Teknik sample judgment sampling adalah sampel yang di pilih dari masalah yang dikembangkan, dan penyesuaian guna mencapai tujuan (Husen, 2019). Menggunakan sampel sejumlah 106 murid (orang), jumlah tersebut termasuk 72 orang murid offline dan 34 murid online.

\section{Variabel Penelitian}

- $\quad \mathrm{X}$ adalah independent variables

- Y adalah dependent varible

- $\quad \mathrm{Z}$ adalah Intervening

\section{Definisi Operasional}

Ada tiga dalam penelitian ini beserta indikatornya yaitu service performance $(\mathrm{X})$ independent, customer satisfaction $(\mathrm{Z})$ intervening, dan customer loyalty $(\mathrm{Y})$ dependen. Definisi masing-masing variabel tesebut akan diuraikan dalam tabel, sebagai berikut: 
Definisi Operasional Variabel

\begin{tabular}{|c|c|c|c|c|}
\hline No & Variabel & Definisi & Indikator & Skala \\
\hline 1. & $\begin{array}{c}\text { Senvice } \\
\text { Performance } \\
\text { (Independent) }\end{array}$ & $\begin{array}{l}\text { Senvice performance } \\
\text { merupakan kinerja dari } \\
\text { pelayanan yang diterima } \\
\text { oleh konsumen itu sendiri } \\
\text { dan menilai kualitas dari } \\
\text { pelayanan yang benar- } \\
\text { benar mereka rasakan } \\
\text { (Cronin dan Taylor, } \\
\text { 1994). }\end{array}$ & $\begin{array}{l}\text { 1. Tangibility } \\
\text { 2. Reliability } \\
\text { 3. Responsiviness } \\
\text { 4. Assurance } \\
\text { 5. Empaty }\end{array}$ & Likert \\
\hline 2. & $\begin{array}{c}\text { Kepuasan } \\
\text { Pelanggan } \\
\text { (Intervening) }\end{array}$ & $\begin{array}{l}\text { Kepuasan pelanggan } \\
\text { merupakan presepsi } \\
\text { terhadap produk atau jasa } \\
\text { yang telah memenuhi } \\
\text { harapannya. } \\
\text { (Irawan, 2008) }\end{array}$ & $\begin{array}{l}\text { 1. Perasaan puas } \\
\text { 2. Terpenuhinya } \\
\text { harapan pelanggan } \\
\text { 3. Selalu membeli } \\
\text { produk }\end{array}$ & Likert \\
\hline 3. & $\begin{array}{l}\text { Loyalitas } \\
\text { Pelanggan } \\
\text { (Dependent) }\end{array}$ & $\begin{array}{l}\text { Loyalitas pelanggan } \\
\text { didasarkanpada wujud } \\
\text { perilaku dari unit-unit } \\
\text { pengambilan keputusan } \\
\text { untuk melakukan } \\
\text { pembeliansecara terus- } \\
\text { menerus terhadap } \\
\text { produk ataujasa suatu } \\
\text { perusahaanyang dipilih } \\
\text { (Griffin, 2005). }\end{array}$ & $\begin{array}{l}\text { 1. Melakukan } \\
\text { pembelian berulang } \\
\text { (makes regular } \\
\text { repeat purchases) } \\
\text { 2. Membeli antar lini } \\
\text { produk atau jasa } \\
\text { ((purchases across } \\
\text { product and senvice } \\
\text { lines) } \\
\text { 3. Merekomendasikan } \\
\text { kepada orang lain } \\
\text { (refers others) } \\
\text { 4. Menunjukkan } \\
\text { kekebalan terhadap } \\
\text { daya tarik pesaing } \\
\text { (demonstrates } \\
\text { immunity to the pull } \\
\text { of the competition). }\end{array}$ & Likert \\
\hline
\end{tabular}

Sumber-: Data diolah, 2020

\section{Metode Analisis Data}

Uji instrument penelitian:

- Validitas Test

\section{- Reliabilitas Test}

Tools yang digunakan untuk menyelesaikan research ini menggunakan SEM AMOS 25 dalam

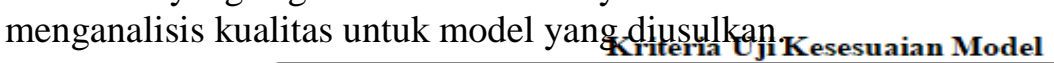

\begin{tabular}{|c|c|c|}
\hline $\begin{array}{c}\text { Indeks Goodness Of } \\
\text { Fit }\end{array}$ & $\begin{array}{l}\text { Nilai Yang } \\
\text { Diharapkan }\end{array}$ & Keterangan \\
\hline Chi-Square & $\leq 0,05$ & $\begin{array}{l}\text { Jika nilai chi-square kurang dari } 0,05 \\
\text { maka nilai tersebut dinyatakan tidak } \\
\text { baik begitupun sebaliknya. }\end{array}$ \\
\hline CNIN/DF & $<2,0$ & $\begin{array}{l}\text { Nilai yang direkomendasikan untuk } \\
\text { menerima kesesuaian model } \\
\text { CNIN/DF }<2,0\end{array}$ \\
\hline RMSA & $<0,08$ & $\begin{array}{l}\text { Nilai RMSEA }<0,08 \text { mengidikasikan } \\
\text { indeks yang baik untuk menerima } \\
\text { kesesuaian model. }\end{array}$ \\
\hline GFI & Mendekati 1 & $\begin{array}{l}\text { Nilai yang mendekati } 1 \\
\text { mengisyaratkan indeks yang baik. }\end{array}$ \\
\hline AGFI & $>0,09$ & $\begin{array}{l}\text { Nilai yang direkomendasikan adalah } \\
\text { AGFI }>0,90\end{array}$ \\
\hline CFI & $>0,95$ & $\begin{array}{l}\text { Nilai yang berada pada rentan } 0 \\
\text { sampai dengan } 1 \text { dan nilai yang } \\
\text { mendekati } 1 \text { memiliki tingkat } \\
\text { kesesuaian yang baik. Nilai } \\
\text { penerimaan yang direkomendasikan } \\
\text { adalah CFI }>0,95\end{array}$ \\
\hline TLI & $>0,95$ & $\begin{array}{l}\text { Nilai yang direkomedasikan adalah } \\
>0,95\end{array}$ \\
\hline
\end{tabular}




\section{Pengujian Sobel Test}

Untuk mempermudah cara mengihutng uji-z, jika kita dapat memnafaatkan online calculator pengujian hipotesis mediasi yang tersaji dalam website http://www.danielshoper.com/ atau dihitung secara manual, yaitu :

$$
z=\frac{a b}{\sqrt{\left(b^{2} \mathrm{SE}_{a}^{2}\right)+\left(a^{2} \mathrm{SE}_{b}^{2}\right)}}
$$

\section{HASIL DAN PEMBAHASAN}

\section{Uji Validitas}

\begin{tabular}{|c|c|c|c|c|c|}
\multicolumn{7}{c|}{ Hasil Uji V aliditas } \\
\hline \multirow{4}{*}{$\begin{array}{c}\text { Variabel } \\
\text { Service } \\
\text { performance } \\
\text { (X) }\end{array}$} & $\mathrm{Item}$ & $\mathrm{r}$ hitung & $\mathrm{r}$ tabel & $\begin{array}{c}\text { Koef. } \\
\text { Signifikansi }\end{array}$ & Keterangan \\
\cline { 2 - 6 } & $\mathrm{X} 2$ & 0,728 & 0,1909 & 0,000 & Valid \\
\cline { 2 - 6 } & $\mathrm{X} 3$ & 0,797 & 0,1909 & 0,000 & Valid \\
\cline { 2 - 6 } & $\mathrm{X} 4$ & 0,767 & 0,1909 & 0,000 & Valid \\
\hline \multirow{4}{*}{$\begin{array}{c}\text { Kepuasan } \\
\text { Pelanggan } \\
(\mathrm{Z})\end{array}$} & $\mathrm{Z} 1$ & 0,764 & 0,1909 & 0,000 & Valid \\
\cline { 2 - 6 } & $\mathrm{Z} 2$ & 0,850 & 0,1909 & 0,000 & Valid \\
\cline { 2 - 6 } & $\mathrm{Z} 3$ & 0,850 & 0,1909 & 0,000 & Valid \\
\hline \multirow{4}{*}{$\begin{array}{c}\text { Loyalitas } \\
\text { Pelanggan } \\
(\text { Y) }\end{array}$} & $\mathrm{Y} 1$ & 0,790 & 0,1909 & 0,000 & Valid \\
\cline { 2 - 6 } & $\mathrm{Y} 2$ & 0,763 & 0,1909 & 0,000 & Valid \\
\cline { 2 - 6 } & $\mathrm{Y} 3$ & 0,744 & 0,1909 & 0,000 & Valid \\
\cline { 2 - 6 } & $\mathrm{Y} 4$ & 0,720 & 0,1909 & 0,000 & Valid \\
\hline
\end{tabular}

Sumber: Diolah dari SPSS 24

Semua item yang digunakan untuk mengukur variabel service performance, customer satisfaction dan customer loyalty adalah correlation coefficient $>0,1909$ serta koefisien signifikansi yaitu 0,000 lebih kecil dari $<5 \%$. Sehingga semua item yang digunakan sebagai pengukur dari variabel service performance, customer loyalty serta semuanya Valid.

\section{Uji Reliabilitas}

Hasil Uji Reliabilitas

\begin{tabular}{|c|c|c|c|}
\hline Variabel & Cronbach's Alpha (a) & $\begin{array}{c}\text { Standar } \\
\text { Reliabilitas }\end{array}$ & Keterangan \\
\hline $\begin{array}{c}\text { Service } \\
\text { performance }\end{array}$ & 0,822 & 0,70 & Reliable \\
\hline $\begin{array}{c}\text { Kepuasan } \\
\text { Pelanggan }\end{array}$ & 0,848 & 0,70 & Reliable \\
\hline $\begin{array}{c}\text { Loyalitas } \\
\text { Pelanggan }\end{array}$ & 0,765 & 0,70 & Reliable \\
\hline
\end{tabular}

Sumber: Diolah dari SPSS 24

Menunjukkan nilai Cronbach's Alpha (a) > nilai Standar Reliabilitas yakni sebesar 0,70 sehingga penelitian dapat di teruskan.

\section{Hasil Asumsi Model}




\section{Uji Normalitas}

Hasil Pengujian Normalitas

\begin{tabular}{|c|c|c|c|c|c|c|}
\hline \multicolumn{7}{|c|}{ Hasil Pengujian Normalitas } \\
\hline Variable & Min & max & skew & c.r. & kurtosis & c.r. \\
\hline Y4 & 2,000 & 5,000 &,- 593 & $-2,494$ &,- 662 & $-1,391$ \\
\hline Y3 & 3,000 & 5,000 &,- 376 & $-1,581$ &,- 921 & $-1,935$ \\
\hline Y2 & 2,000 & 5,000 &,- 642 & $-2,700$ &, 299 &, 627 \\
\hline Z3 & 2,000 & 5,000 &,- 845 & $-3,552$ &,- 028 &,- 059 \\
\hline Z2 & 2,000 & 5,000 &,- 323 & $-1,357$ &,- 834 & $-1,753$ \\
\hline Z1 & 2,000 & 5,000 &,- 542 & $-2,280$ &,- 190 &,- 400 \\
\hline X5 & 2,000 & 5,000 &,- 209 &,- 878 &,- 744 & $-1,563$ \\
\hline X4 & 2,000 & 5,000 &,- 399 & $-1,679$ &,- 706 & $-1,483$ \\
\hline X3 & 2,000 & 5,000 &,- 470 & $-1,975$ &,- 686 & $-1,441$ \\
\hline X2 & 2,000 & 5,000 &,- 288 & $-1,211$ &,- 610 & $-1,283$ \\
\hline X1 & 2,000 & 5,000 &,- 427 & $-1,796$ &,- 648 & $-1,361$ \\
\hline Multivariate & 2,000 & 5,000 &,- 264 & $-1,111$ &,- 787 & $-1,653$ \\
\hline
\end{tabular}

Normalitas test data penelitian dapat dilakukan melihat nilai CR pada skewness, diharapkan $C R$ skewness berada - 2,58 s/d +2,58. Jika terdapat CR tidak masuk -2,58 hingga 2,58, dapat ditoleransi apabila CR di kurtosis masih antara $-2,58$ sampai $+2,58$. Tabel pengujian normalitas menunjukkan bahwa nilai CR pada skewness dari semua indikator masih di kisaran 2,58, berarti sebaran data dapat dikatakan terdistribusi normal, sehingga dapat dilakukan regresi dengan model SEM.

\section{Outliers}

Jarak Mahalanobis Data Penelitian

\begin{tabular}{|c|c|c|}
\hline Nomor Observasi & Jarak Mahalanobis & $\begin{array}{c}\text { Jarak Mahalanobis } \\
\text { Kritis 12:0,001 }\end{array}$ \\
\hline 52 & 32,870 & \multirow{2}{*}{3} \\
\hline 26 & 24,717 & \multirow{2}{*}{32,90949} \\
\hline 33 & 23,824 \\
\hline- & - \\
\hline- & - \\
\hline- & - \\
\hline 46 & 5,919 \\
\hline
\end{tabular}

Malahanobis jarak di mana nilai p lebih dari 0,001 digunakan untuk uji multivariate outliers. Kemudian Malahanobis ini dengan menggunakan $X^{2}$ mulai untuk di evaluasi, menggunakan derajat bebas 32,909413 dan menggunakan 12 indikator. Tabel 4.7 di atas menunjukan bahwa tidak terdapat outlier, dikarenakan observasi semuanya mempunyai jarak mahalanobis $\leq 32,909413$. Terjawab jika responden tanggap dengan jawaban di kuesioner cenderung bervariasi atau baik.

\section{Analisis Goodness of Fit Model}

Dengan menggunakan AMOS 25 (SEM), sebagai berikut:

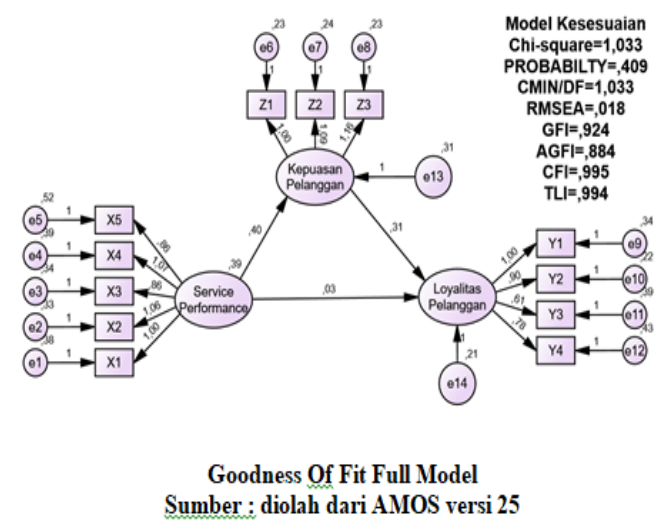

Berdasarkan Gambar Goodness of fit full mode yang diolah oleh SEM AMOS 25 diatas dapat diringkas sebagai berikut: 
Indeks Kesesuaian Model

\begin{tabular}{|c|c|c|c|}
\hline $\begin{array}{l}\text { Goodness-of Fit } \\
\text { of Fit Index }\end{array}$ & Value & $\begin{array}{l}\text { CUT-OF } \\
\text { FALUE }\end{array}$ & KETERANGAN \\
\hline$X^{2}$ (Chi Square) & 1,033 & $\begin{array}{c}\text { Diharapkan } \\
\text { kecil }\end{array}$ & Baik \\
\hline Probability & 0,409 & $\geq 0,05$ & Baik \\
\hline RMSEA & 0,018 & $\leq 0,08$ & Baik \\
\hline GFI & 0,924 & $\geq 0,90$ & Baik \\
\hline AGFI & 0,884 & $\geq 0,90$ & Marginal \\
\hline CFI & 0.995 & $\geq 0,95$ & Baik \\
\hline $\mathrm{CMIN} / \mathrm{DF}$ & 1,033 & $\leq 2,00$ & Baik \\
\hline TLI & 0,994 & $\geq 0,95$ & Baik \\
\hline
\end{tabular}

Berdasarkan hasil indeks kesesuaian model di atas terlihat bahwa hanya AGFI yang memiliki nilai $0,884<0,90$. Namun masih dapat di toleransi dengan nilai marginal dan hal tersebut dinyatakan masih aman memenuhi kriteria.

\section{Pengujian Hipotesis}

Model regresi di gunakan untuk pengujian hipotesis. Sementara untuk standardized Regression Weight adalah output dari AMOS 25 .Sementara itu confirmatory analize factor di tunjukkan sebagai berikut:

\section{Hasil Analisis Konfirmatori Faktor}

\begin{tabular}{|c|c|c|c|c|c|c|}
\hline \multicolumn{3}{|c|}{ Variabel } & Estimate & S.E. & C.R. & $\mathbf{P}$ \\
\hline Kepuasan_Pelanggan & $<--$ & Service_Performance & .398 & .117 & 3.403 & 0,000 \\
\hline Loyalitas_Pelanggan & $<--$ & Service_Performance & .027 & .113 & .236 & .813 \\
\hline Loyalitas_Pelanggan & $<--$ & Kepuasan_Pelanggan & .314 & .126 & 2.497 & .013 \\
\hline
\end{tabular}

Sumber: Data diolah, 2021

Dapat di deskripsikan sebagai berikut pada:

\section{$\mathrm{H}_{1}$ Service performance terhadap customer loyalty}

Nilai koef. regresi service performance terhadap customer loyalty dengan nilai estimate 0,027 , Sig. (P) 0,813 > besar dari signifikasi 5\%. Mengartikan hipotesis pertama hubungan Service Performance tidak mempunyai pengaruh terhadap customer loyalty pada Crystal Learning Center di Kota Jayapura. $\mathrm{H}_{2}$ Service Performance Terhadap Customer satisfaction

Nilai koef.regresi Service Performance terhadap customer satisfaction dengan nilai estimate sebesar 0,398 terhadap customer satisfaction < kecil dari sig.0,05. Service Performance mempunyai pengaruh dengan customer satisfaction pada bimbingan belajar Crystal Learning Center dikota jayapura .

\section{$\mathrm{H}_{3}$ Customer satisfaction terhadap Loyalitas Pelanggan}

Nilai koefisien regresi Customer satisfaction pada customer loyalty mempunyai nilai estimate o,314 tehadap Loyalitas Pelanggan lebih kecil dari taraf signifikasi 5\%. Mengandung arti kepuasan berpengaruh terhadap customer loyalty pada bimbingan belajar Crystal Learning Center dikota jayapura.

\begin{tabular}{|c|c|c|c|}
\hline Analisis Pengaruh Langsung (Direct) \\
\hline $\begin{array}{c}\text { Service } \\
\text { Verformance }\end{array}$ & $\begin{array}{c}\text { Kepuasan } \\
\text { Pelanggan }\end{array}$ & $\begin{array}{c}\text { Loyalitas } \\
\text { Pelanggan }\end{array}$ \\
\hline $\begin{array}{c}\text { Kepuasan } \\
\text { Pelanggan }\end{array}$ & 0,398 & 0,000 & 0,000 \\
\hline $\begin{array}{c}\text { Loyalitas } \\
\text { Pelanggan }\end{array}$ & 0,027 & 0,314 & 0,000 \\
\hline
\end{tabular}

Customer loyalty pengaruh langsungnya dengan customer satisfaction 0,314 yang berarti bahwa ketika seseorang puas dengan layanan atau produk yang dibelinya, secara otomatis akan tercipta loyalitas pelanggan dengan bukti mereka akan membeli berulang-ulang. selanjutnya, service performance direct effect dengan customer loyalty 0,027 . 


\section{$\mathrm{H}_{4}$ Service Performance hubungan Customer Loyalty juga Customer Satisfaction sebagai mediasi \\ Variabel Service Performance pada customer loyalty dan variable memediasi Customer satisfaction dengan nilai $Z=2.01032337$ yang berarti peningkatan pada variabel intervening menjembatani hubungan dari service performance kepada customer loyalty.}

Analisis Pengaruh Tidak Langsung (Indirect)

\begin{tabular}{|c|c|c|c|}
\hline Variabel & $\begin{array}{c}\text { Service } \\
\text { Performance }\end{array}$ & $\begin{array}{c}\text { Kepuasan } \\
\text { Pelanggan }\end{array}$ & $\begin{array}{c}\text { Loyalitas } \\
\text { Pelanggan }\end{array}$ \\
\hline $\begin{array}{c}\text { Kepuasan } \\
\text { Pelanggan }\end{array}$ & 0,000 & 0,000 & 0,000 \\
\hline $\begin{array}{c}\text { Loyalitas } \\
\text { Pelanggan }\end{array}$ & 0,125 & 0,000 & 0,000 \\
\hline
\end{tabular}

Sumber: Data diolah, dengan menggunakan AMOS 25, Tahun 2021

Dapat dijelaskan bahwa besar indeirect effect yaitu performance services dengan loyalty customer adalah 0,125. Perbandingan nilai hubungan secara langsung dan tidak langsung, dilihat pada table berikut:

Hubungan Direct Dan Indirect

\begin{tabular}{|l|c|c|}
\hline \multicolumn{1}{|c|}{ Hubungan antar Variabel } & \multicolumn{1}{c|}{$\begin{array}{c}\text { Direct } \\
\text { (Langsung) }\end{array}$} & $\begin{array}{c}\text { Indirect } \\
\text { (Tidak Langsung) }\end{array}$ \\
\hline $\begin{array}{l}\text { Service peformance } \rightarrow \text { Loyalitas } \\
\text { Pelanggan }\end{array}$ & $\mathbf{0 , 0 2 7}$ & $\mathbf{0 , 1 2 5}$ \\
\hline $\begin{array}{l}\text { Service performance } \rightarrow \text { Kepuasan } \\
\text { Pelanggan } \\
\rightarrow \text { Loyalitas Pelanggan }\end{array}$ & \\
\hline $\begin{array}{l}\text { Kesimpulan : Dalam penelitian ini memiliki nilai Direct 0,027 < Indirect 0,155 } \\
\text { hal tersebut membuktikan bahwa penelitian ini full Mediasi artinya, variabel } \\
\text { kepuasan pelanggan mampu menjembatani hubungan antara service performance } \\
\text { terhadap loyalitas pelanggan pada bimbingan belajar crystal learning center: }\end{array}$ \\
\hline
\end{tabular}

Sumber: diolah, 2020

Hasil Uji Sobel Test

Dapat dilakukan secara manual maupun otomatis melalui http://www.danielshoper.com/ sebagai berikut:

$$
\begin{aligned}
\mathbf{Z} & =\frac{a b}{\sqrt{\left(b^{2} S E_{a}^{2}\right)+\left(a^{2} S E_{b}^{2}\right)}} \\
& =\frac{0,398 \times 0,314}{\sqrt{\left(0,314^{2}\right)\left(0,117^{2}\right)+\left(0,398^{2}\right)\left(0,126^{2}\right)}} \\
& =\frac{0,124972}{\sqrt{(0,098596)(0,013689)+(0,15404)(0,015876)}} \\
& =\frac{0,124972}{\sqrt{0,00134968064+0,0025148219}} \\
& =\frac{0,124972}{\sqrt{0,00386450254}} \\
& =\frac{0,124972}{0,06216512318} \\
& \mathbf{Z}=2,01032337
\end{aligned}
$$




\section{Atau cara otomatis :}

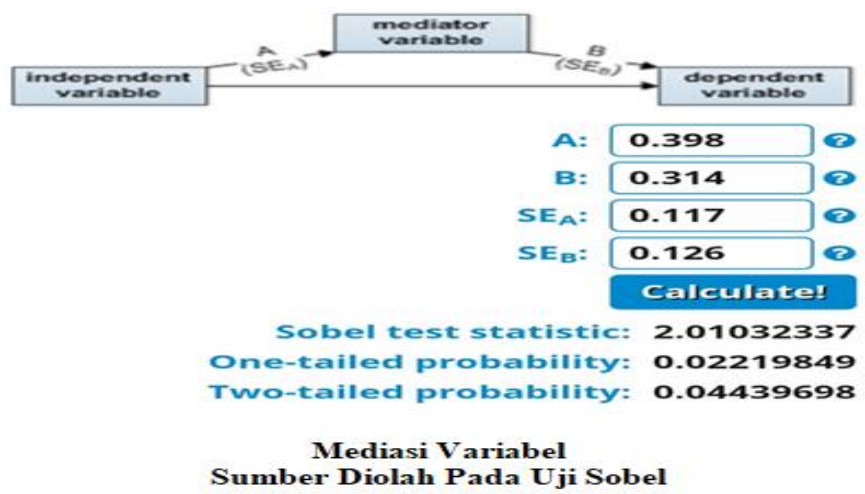

Berdasarkan perhitungan sobel test secara manual dan sobel test statistic menunjukan bahwa terdapat nilai z yang sama. Artinya bahwa, sumber Gambar 4.2 di atas dapat menunjukan hasil nilai z sebesar $2,01032337 \geq 1,98304$. Nilai probability-one tiled 0,02219849 kemudian probability two-tailed 0,04439698 kurang dari 0,05 . Sehingga variabel customer satisfaction potif dan signifikan untuk menjadi variabel intervening. Penelitian ini berarti variabel service performance memberikan pengaruh langsung hubungan variabel customer satisfaction dan customer satisfaction dapat diterima untuk memediasi secara langsung.

\section{Pembahasan Hasil Penelitian}

\section{Service performance terhadap Customer Loyalty}

Penelitian mendapatkan hasil bahwa service performance tidak mempunyai pengaruh terhadap customer loyalty pada crystal learning center di Kota jayapura. Service performance pada setiap perusahaan mempunyai peran yang sangat penting. Karena sebaik apapun pelayanan yang diberikan crystal learning center kepada para murid belum tentu bisa menciptakan loyalitas jika apa yang diinginkan murid belum sesuai harapannya. Ini mengandung arti, bahwa sebaik apapun pelayanan yang diberikan jika tidak bisa menciptakan kepuasan maka tidak akan menghadirkan loyalitas.

\section{Service Performance Terhadap Customer satisfaction}

Penelitian ini mendapatkan ada pengaruh antara customer satisfaction juga service performance pada crystal learning center di Kota Jayapura. Ketika penyedia jasa mampu memberikan pelayanan yang dibutuhkan oleh pelanggannya maka mereka akan merasa puas, hal tersebut karena penyedia jasa adalah pemenuh ekspektasi pelanggan. Crystal learning center telah memberi layanan prima kepada muridnya, kepuasan murid terlihat dari nilai murid yang semakin baik, murid semangat berangkat les dll.

\section{Customer satisfaction terhadap Loyalitas Pelanggan}

Dari hasil yang di dapat pengaruh customer loyalty dan customer satisfaction adalah positif. Murid crystal learning center bahagia dengan layanan yang dirasakan, terbukti adanya frekwensi waktu bergabung di atas 3 tahun bahkan lebih dari itu. Ketika mereka loyal maka rencana membeli kembali akan terjadi. Bagi seorang pemasaran hal yang diutamakan bukanlah bagaimana ia menawarkan produknya kepada pelanggan, akan tetapi bagaimana mereka bisa menciptakan nilai pelanggan (Customer Value) jika suatu produk bisa memiliki nilai tambah maka dapat dikatakan loyal dan puas bagi pelanggan.

\section{Service Performance, Customer Loyalty dan melalui mediasi Customer Satisfaction}

Memberikan hasil diketahui service performance mempunyai pengaruh yang baik pada loyalty customer jika customer satisfaction adalah mediasi di crystal learning center dikota jayapura. Pelayanan yang diberikan crystal learning center mampu memberikan kepuasan bagi pelanggan oleh sebab itu pelanggan atau murid merasa loyal. Hal tersebut sejalalan dengan hasil penelitian (Anggayani \& Osin, 2017) ; (Husodho, 2015) ; dan (Sumarwan et al., 2011). 


\section{PENUTUP}

\section{Simpulan}

Service performance mempunyai hubungan pada customer loyalty dengan satisfaction customer memediasi bimbingan belajar crystal learning center dikota jayapura. Hal tersebut menunjukan pelanggan mampu menciptakan satisfaction, karena begitu konsumen tercukupi kepuasannya, mereka loyal dengan pelanggan loyal mereka akan membeli produk secara terus-menerus.

\section{DAFTAR PUSTAKA}

Anggayani, N. W., \& Osin, R. F. (2017). Pengaruh Service Performance terhadap Nilai Sekolah Kepuasan dan Loyalitas Pelajar pada Smk Pariwisata Triatma Jaya Tabanan. Jurnal Manajemen Pelayanan Hotel Akademi Komunitas Manajemen Perhotelan Indonesia, 1(1), 28-35. https://doi.org/10.37484/manajemen_pelayanan_hotel.v1i1.31

Antika, H. W., Farida, N., \& Listyorini, S. (2015). Pengaruh Service Performance dan Customer Value Sebagai Variabel Intervening ( Studi pada Pengguna Jasa PT Herona Express Semarang ) Email : Heppy.cantique@gmail.com Pendahuluan Perubahan dalam suatu tatanan kehidupan berjalan seiring dengan perkembangan. Administrasi Bisnis, Fakultas Ilmu Sosial Dan Politik, 1(1), 1-12.

Carsel, S. (2018). Metodologi Penelitian Kesehatan dan Pendidikan (A. Adriani (ed.)). Penebar Media Pustaka.

Daryanto. (2013). Sari Kuliah Manajemen Pemasaran (Hisar Martin (ed.)). PT Sarana Tutorial Nurani Sejahtera.

Ferdinan, A. (2014). Structural Rquation dalam Penelitian Manajemen (A. Book (ed.)). Badan Penerbit Universitas Diponegoro.

Ferdinand. (2014a). Metode Penelitian Manajemen. Universitas Diponegoro.

Ferdinand, A. (2014b). Structural Equation Modeling (5th ed.). Universitas Diponegoro.

Ghozali, \& Fuad. (2005). Structural Equation Modeling: Teori, Konsep, dan Aplikasi. Universitas Diponegoro.

Griffin, J. (2005). Customer Loyalty Menumbuhkan dan Mempertahankan Kesetiaan pelanggaP (Y. Sumihartini, R. Media, \& W. C. Kristiaji (eds.)). Erlangga.

Huda, N., Novarini, Mardoni, Y., \& Sara, C. P. (2015). Zakat Prespektif Mikro-Makro Pendekatan Riset (1st ed.). kencana.

Husodho, W. R. (2015). Pengaruh Customer satisfaction terhadap Loyalitas Pelanggan pada Obyek Wisata Dumilah Water Park Madiun. Jurnal Ilmiah Ekonomi Dan Pembelajarannya, 3(2), 176189. https://doi.org/10.25273/equilibrium.v3i2.667

Irawan, H. (2008). Membedah Stragtegi Customer satisfaction (Cetakan Pe). PT. Gramedia.

Jamaluddin. (2019). Pengaruh Service Perfomance dan Kualitas Produk terhadap Kepuasan Nasabah dalam Membentuk Loyalitas Nasabah PT. Bank Muamalat Indonesia, Tbk. Jurnal Hukum Ekonomi Syariah, 11(1), 1-22. https://doi.org/10.37035/mua.v11i1.1947

Kotler, \& Keller. (2008). Manajemen Pemasaran (12th ed.).

Kotler, P., Ang, S. H., Leong, S. M., \& Tan, C. T. (2000). Manajemen Pemasaran (1st ed.). Jenni Purba.

Kotler, P., \& Armstrong, G. (2001). Prinsip-Prinsip Pemasaran (1st ed.).

Noch, M. Y., \& Rasyid, A. (2012). Metodologi Penelitian (A. I. Lubis \& H. Hasugian (eds.); 1st ed.). Perdana Publishing.

Nugroho, A. W., \& Sudarwanto, A. (2013). Pengaruh Kinerja Layanan, Kepercayaan dan Kepuasan terhadap Customer loyalty dalam menggunakan Jasa Pengiriman Barang. Diponegoro Journal of Management, 2(3), 1-9. http://ejournal-s1.undip.ac.id/index.php/dbr

Priyatno, D. (2012). Cara Kilat Belajar Analisis Data Dengan SPSS 20. Andi Offset.

Purwanto, A. B. (2015). Pengaruh Service Performance dan Relationship Marketing terhadap Customer loyalty. Fakultas Ekonomi, 10(1), 88-101. http://tekno.liputan6.com

Rahmawaty, A. (2016). Pengaruh Service Performance, Kepuasan, Trust dan Komitmen terhadap Loyalitas Nasabah di Bank Syari'Ah Mandiri Kudus. Inferensi, 5(1), 53-80. https://doi.org/10.18326/infs13.v5i1.53-80

Riyato, S., \& Hartawan, A. A. (2020). Metode Riset Peneitian Kuantitas (1st ed.).

Rizal, A. (2020). Manajemen Pemasaran di Era Masyarakat Industri 4.0 (1st ed.). Group Penerbit CV Budi Utama.

Sangadji, E. M., \& Sopiah. (2010). Metodelogi Penelitian-Pendekatan Praktis dalam Penelitian (1st 
ed.). Andi.

Schiffman, L. G., \& Kanuk, L. L. (2007). Perilaku Konsumen (7th ed.). PT Macanan Jaya Cemerlang.

Sofi, N., Arifin, R., \& Priyono, A. A. (2017). Pengaruh Ecommerce Strategy, Service Performance dan Kepuasan sebagai Moderating Variable terhadap Loyalitas Nasabah Bank BRI UNISMA Malang. Riset Manajemen, 1-10, 45-54.

Sudarsono, H. (2020). Manajemen Pemasaran (1st ed.). CV Pustaka Abadi.

Sugiyono. (2004). Metode Penelitian Bisnis (A. Nuryanto.S.Pd (ed.); 6th ed.). Alvabeta.

Sumarwan, U., Jauzi, A., Mulyana, A., Karno, B. N., Mawardi, P. K., \& Nugroho, W. (2011). Riset Pemasaran dan Konsumen (1 (ed.)).

Wardhana, A. A., Hudayah, S., \& Wahyuni, S. (2017). Analisis Kinerja Layanan dan Customer satisfaction terhadap loyalitas Nasabah Analysis of Service Performance and Customer Satisfaction on Customer Loyalty. Jurnal Manajemen, 9(1), 1-7.

Wijayanti, T. (2017). Marketing Plan dalam Bisnis (3rd ed.). PT Elex Media Komputer. 